\title{
The Effect of LCCs' e-Business and e-Management Strategies by Investigating Determinants on Southern Taiwan
}

\author{
Wan-Yun Tina Cheng*, Chen-Cheng Chen \\ College of Management, National Kaohsiung First University of Science and Technology, Taiwan. \\ * Corresponding author. Tel: +886 7 6011000; email: u0128902@nkfust.edu.tw \\ Manuscript submitted February 12, 2016; accepted August 9, 2016. \\ doi: 10.17706/ijeeee.2016.6.3.146-161
}

\begin{abstract}
Budget airlines, also named as low cost carriers (LCC) in Taiwan, have had great impact in Europe, America and have stimulated new demand since the orientation of Southwest Air in 1973. The market share of LCCs has gradually increased in each region and grown particularly within Asia-Pacific. The first LCCs entered the Asian air transport market in the early 2000s; meanwhile the first budget airline commencing its business in Taiwan was Jetstar in 2004. Many researches were focused on the comparison between full service carriers (FSC) and LCCs; competitive strategy for FSCs to outstand the market. However, only few studies were focused on Taiwan's LCCs of their decisive determinants. Actually, none was specifically focused on passengers' perceived concept and attentive factors triggering passengers' decisions in Taiwan. In this paper, factors analysis based on customers' satisfaction to purchasing behavior was conducted. The factors were integrated other researches factors about airline satisfaction and creatively considering one factor, word of mouth (WOM) as another direct construct to motivate attention behavior. The survey was conducted with 284 valid samples by PLS-SEM, a factor construct analysis tool. The survey of LCCs about determinants was to investigate customers' perceived concepts toward LCCs in Taiwan. The result showed price is the same determinants concern for LCC. Another interesting factor was WOM can be a key factor influencing Taiwanese purchasing behavior. This study provides novel insight regarding LCC passengers' concepts and behavioral intention, as well as managerial analysis and research implications for LCCs business reference.
\end{abstract}

Key words: LCC (low cost carriers), FSC (full service carriers), word of mouth (WOM), satisfaction, intention.

\section{Introduction}

Low-cost carriers, also named as budget airlines, have had great impact in Europe, America and stimulated new demand [1] since the orientation of Southwest Air in 1973. The market share of LCCs has gradually increased in each region. That is to say, the increasingly competitive air travel environment has influenced consumer demand patterns [2]-[4]. Many researches focused on the comparison between full schedule carriers (FSC) and LCCs or competitive strategy for FSCs to outstand the market. Recently some investigations have been located to discuss the factors [2], [5]. Also some researchers claimed that LCC firms can ensure long-term success by developing the determinants of passenger loyalty [6]. With so many investigations, LCCs' perceived preferences are proven to be significant. However, are the Asian regions still 
similar to others?

The first LCCs entered the Asian air transport market in the early 2000s. As Pearson and Merkert [7] stated that LCCs are growing particularly within Asia-Pacific. In 2001, the LCCs domain rate only 8\%, and it largely came to $26.1 \%$ in 2012. In Europe market, the occupation rate is $36.6 \%$; and $30.1 \%$ in North America. Among all, the Asia market, lately stepped in but potentially profitable also rated $24.1 \%$. There are magnificent potential markets in Asia. Take into account as the focus is that Taiwan, set up his own LCC in this October, 2014. It means that LCCs are stepping as budding carriers. The first LCC into Taiwan market in 2004, Jetstar Air, encroached into the route of Taiwan vv Singapore with around USD29 sector airfare, almost half price of FSCs. In 2012 the market share in Taiwan only 3.9\% (CAA, Taiwan) and until this December, 2014, there are total thirteen LCCs and operate sixteen schedule routes and the market share rounds up to $7.2 \%$. However, few studies were focused on Asia's LCCs of their decisive determinants, especially on consumers' perceived concepts and factors really triggering consumers' decisions. In this paper, the study was specifically harvested all efforts to investigate Taiwan's consumers pattern and to realize their possible chance. To what extend LCCs can really integrate Taiwan's perceived concept and determinants. All the findings can be useful for the LCCs to promote air transportation share.

Ever since there are already plenty of studies about LCC, or airline services, or service satisfaction. However, few studies focus on LCC in Asia, even in Taiwan. Also many influencing variables have been discussed and most of them are all significant to the end. With so many constructs, organized filtering ones should be selected to be discussed as below. Therefore, in this study, we developed a relationship business model by examining people's perceived concepts and determinants people may strongly concern in Taiwan. The determinants are Price (FP), Assurance (AS), Flight schedule (FS), Facility service (FA), Customization (CS). We examined the above factors if with significance influence toward Satisfaction (SAT). While satisfaction is the concept synthesis deriving from factors to attract Intentions (INT) to purchase LCCs. Intention can be evaluated on half of antecedents' significant performance. Another special factor is Word of mouth (WOM) in which we examined the relationship with satisfaction and intention. Perceived concept is people's pre-assumption knowledge in Taiwan; while WOM is the receiving concept from outside influence. By knowing the perceived concept, LCCs or strategy deciders can conceive people's ideas and improve the enhancement via verbal propaganda. Furthermore, WOM is the influenced concept received from related friends or closed ones. The LCCs or strategy managers can make good use of WOM to promote their business in Taiwan if the relationship is significant.

Thus, this study organized a LCC business model, listed as the following: FP $\rightarrow$ SAT, AS $\rightarrow$ SAT, FS $\rightarrow$ SAT, FA $\rightarrow$ SAT, CS $\rightarrow$ SAT, SAT $\rightarrow$ INT, SAT $\rightarrow$ WOM, WOM $\rightarrow$ INT. In the following chapter, all the determinants are reviewed and defined so that the variances can be theoretical supported.

\section{Theoretical Background of Determinants}

\subsection{Determinants: Antecedents of Satisfaction}

\subsubsection{Price}

Price, defined in Oxford Dictionary as the amount of money expected, required, or given in payment for something. Also the focused price is defined by monetary cost; that is, the value of monetary is considered to pay something expected. At the timing of expecting something, how much value is paid to gain the attraction. Undoubtedly price making becomes an essential strategy in roping in customers. LCCs, sometimes called as intruders of airline business, definitely perceive the key point to encroach the competitive and crowded air business. All the LCC flying hours are within 3 to 4 hours. Generally, the LCCs provide point-to-point service on short-haul with attractive competitive airfare [8]. Low and budget price is the strategy for the market entry to break out in an already occupied and almost balanced-arranged market. 
LCCs accentuate prominently by providing aggressive pricing strategy [2], [9]-[13]. As the name, Low Cost Carriers, low airfare price, considerably surprising, turns into the main successful factor for LCCs to break through the market. Even the FSC (full schedule carriers) sense the threat and enforce to innovate new strategy for survival [1], [14].

Price, a winning determinant, becomes a sounding logo for LCCs' passengers. Coming with LCCs' entrance, the low airfare competition indeed bring some impact on travelers' choice. The increasingly competitive air travel environment has influenced consumer demand patterns [3], [4]. LCCs design the business strategy to attract the ethic group who enjoy travelling, but with limited budget. The group segmentation is composed of young adult and low-margin passengers [15]. Somehow the group is called as backpackers, a term to define as travelling addict with low budget and lack of economic capacity. Also the customer segment is viewed as "downmarket", that is an emphasis on dynamic pricing tactics. The majority group concerns most "price". When the essential consideration is fully achieved, the expecting satisfaction is completely met. Therefore, the hypothesis is reasonable to list as:

\section{FP positive influence SAT}

\subsubsection{Assurance}

Flight assurance can be viewed as flight reliability. That is an important index to value airline service. According to the report of AQR (Airline Quality Rating), the quality which meant good airline assurance is evaluated on the attributes. Those attributes include: on-time arrival, mishandled baggage, airline safety, passenger complaints (e.g. cancellations, delays, deviations from schedule), reservation, ticketing, and boarding problems. To sum up, the general literature indicates passengers regard of important attributes (listed key attributes related to assurance) as reliability, flight safety assurance, a beneficial frequent flyer programme to be a superior service airline [16]. Comparing with FSC, superior service is not the most concern of LCC, but profit. However, flight secure safety comes up the top priority for every type of airlines. Only passing the secure aviation check, the Aviation Bureau can allow the flight departure. None of passengers will risk life to be on plane. But concerning with price attraction, the assurance soon becomes important only, but not the first considering attraction. That is the hypothesis to be considered as the below.

\section{AS influences SAT}

\subsubsection{Flight schedule, facility service, customization}

The aviation Industry somehow has been identified as one of the more intangible service industries. Except tangible aircraft and measureable airfare price, the other related services as business strategic management are provided to enhance business profits and obtain frequent passengers. All the service images are intangible and difficult to evaluate. In order to measure intangible service, a well-known service measuring instrument was designed, SERVQUAL, proposed by Parasuraman, Zeithaml, \& Berry [17]. The SERVQUAL instrument has been used by several researchers to measure airline service [17]-[19]. By summarizing the service dimensions, three dimensions were extracted respectively with different representative items. Those are Flight schedule, Facility Service and Customization.

Flight schedule can be the time slot designed by airline companies to fit passengers' requirement. More generally speaking, it is summarized as Flight Patterns that include flight schedules, flight frequencies, flight network by Gilbert \& Wong [16] as convenient flights schedules and enough frequencies, availability of global alliance partners' network, non-stop flights to various destinations or expresses as on-time departure, on-time arrival, or no cancelation of flights [14]. All the indicators are focused in heightening 
airline service. However, some service items might cause higher cost, like global alliances and some might not be regulated by LCCs, like convenient flight schedule. LCCs sometimes are designated in remote terminals and with non-competitive time slot by Airport Control [1]. The service might not be coped or designed.

\section{FS negative influence SAT}

Facility service refers to check-in, baggage handling service, in-flight facilities, waiting lounge [16]. The question items include clean and comfortable interior/seat, in-flight entertainment facilities and programs, availability of waiting lounges, In-flight Internet/email/fax/phone facilities [20]. It also includes updated facilities' visual appeal [17], [21], [22]. With the restricted service types by LCCs, some are exclusive. That is to say, facility service is not designed as LCCs' strategy. Actually LCCs choose a single aircraft type over all legs, frequencies and a single price per leg flown [23]. The reason to operate a single aircraft type strategy is to reduce maintenance costs and personnel training. Also there is no need to distinguish between business and leisure travelers directly. For the purpose of yield management, LCCs use yield management to maximize revenues by changing ticket prices over time, a strategy designed to attract as much of the consumer surplus as possible. However, as pre-assumption to capture satisfaction, good facility service is seemingly provided. Therefore, the construct reason might be designed as:

\section{FA negative influence SAT}

Customization including individual attention, anticipation of your travel needs refers to individual attention to passengers, understanding of passengers' specific needs, availability of loyalty programme, availability of frequent flyer programme, availability of air/accommodation packages, availability of travel related partners, e.g. hotels, car rentals [16]. Customization means to offer personal emphasized value to individual who can feel pleasant and warm [24]. Customization is designed to treat passengers as elite with privilege. Only with individual attention and care service, passengers are content with satisfaction. LCCs frankly speaking only provide single service: safely transport passengers from departing place to arrival destination. With some special individual service, like WCHR (wheel chair service) is not mandatory provided (ex. Some official notice from Tiger Air website). With the same possible restriction, the hypothesis might be verified as:

\section{CS negative influence SAT}

\subsection{Determinate of Satisfaction and Intention: WOM (Word of Mouth)}

Word of mouth refers to a flow of information about products, services, or companies from one customer to another [14]. Word of mouth represents an external source of information delivered by experienced customers or trusted customers to which passengers can confirm and be persuaded to stimulate purchasing intention. Another definition of word of mouth is the depth to which customer that obtained a certain level of satisfaction would inform other people about that particular event. As everyone says: one person will complain the bad service at least to 7 persons, and so on.... However the empirical study shows that customers with bad and good experiences will inform up to 11 and 6 people respectively. To be on the good side of effect, it is suggested that customers that have positive experiences are more willing to communicate their feelings to others than those with negative experiences. The impact of word-of-mouth with good recommendation motivates the purchasing intention. About $60 \%$ of sales to new customers are reported to be due to word-of-mouth referrals [25]. Similarly implied in organization activity, positive word-of-mouth 
will result in having good sales, attracts more customers, and reduces customer runaways. Therefore the hypothesis is supposed.

\section{WOM influences INT}

\subsection{Final Antecedents of Intention: Satisfaction}

Satisfaction, word of mouth and purchasing intention (behavior intention) are the most discussed dimensions. As satisfaction, the complexity construct, many definitions have been discussed. Satisfaction is the outcome of buying a product or service, [26] whereby the purchase rewards and costs are compared. Also La [27] noted that customer satisfaction is an antecedent of repurchase intention. Many writers claimed that customer satisfaction may predict future repurchasing behaviors and profitability [28]-[30] Furthermore to say, satisfaction is described the cognitive comparison between the expectations that a passenger holds prior to the purchase or service experience and the actual performance of the service. Customer expectations can be either positive or negative disconfirmation [26]. Disconfirmation derived from passenger satisfaction will deliver either positive or negative communication. The relationship between satisfaction and word of mouth is that satisfied customers generate positive word-of-mouth [22]. That is to say, customer satisfaction stimulates repeat purchases and favorable word-of-mouth. In light of the above discussion, the following hypotheses are proposed:

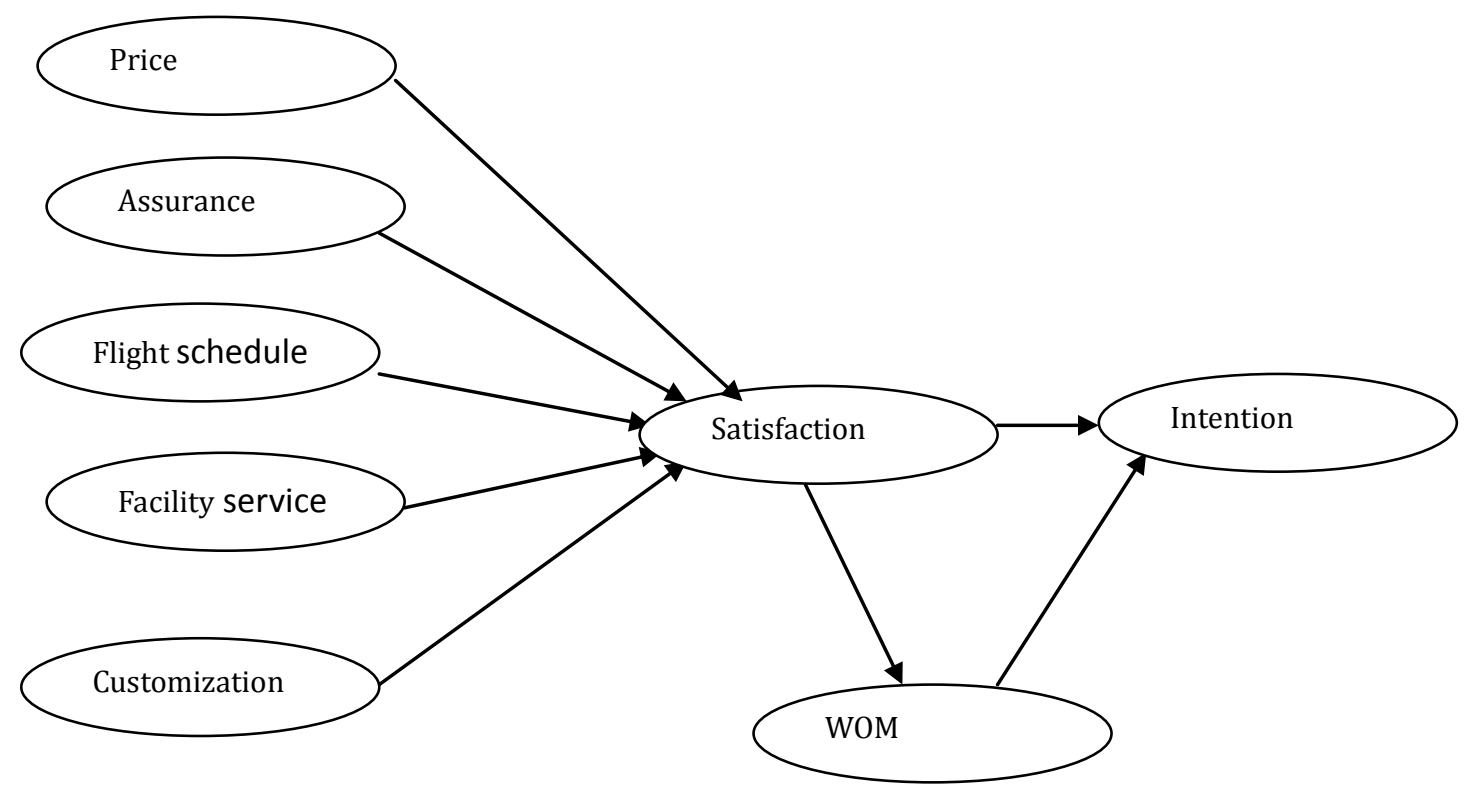

Fig. 1. A business model of LCCs determinant factors in Taiwan.

\section{Empirical Study}

\subsection{Measurement}

We examine survey to conduct eight constructs with respective items, which are modified for LCC context. There are eight constructs in this study: Price (FP), Assurance (AS), Flight schedule (FS), Facility service (FA), Customization (CS), Word of mouth (WOM), Satisfaction (SA) and Intention (INT). With the eight 
constructs, the instrument, a self-completion questionnaire, contains total 26 items in the first beginning. All the items are measured on a five point Likert scale ranging from (1) strongly disagree to (5) strongly agree.

The eight main constructs in this study were operationalized using scales found in extant literature. In order to evaluate the key determinates of LCC satisfaction, we developed total 15 items respectively of five indicators (three for price, three for assurance, three for flight pattern, four for flight facility, and three for customization) from current study [17], [19], [31]. All these indicators were filtered because they better describe the characteristics of airlines business. Whilst three influenced indicators (two for word of mouth, four for satisfaction, and three for intention) are measured with respective items [14], [18], [21], [30], [32]. Table 1 shows the operationalisation of the data collection of the data collection instrument.

Table 1. Operationalisation of the Data Collection Instrument

\begin{tabular}{lll}
\hline \hline Dimension & Item & Source \\
\hline \hline Price & (FP1) Reasonable price & {$[26]$} \\
(FP) & (FP2) Value for money & {$[18]$} \\
& (FP3) Reliable price information & \\
Assurance & (AS1) professional handling & {$[16]$} \\
(AS) & (AS2) secure safety & {$[31]$} \\
& (AS3) robust schedule & {$[14]$} \\
Flight schedule & (FS1) connecting service & {$[18]$} \\
(FS) & (FS2) multi-destinations & {$[16]$} \\
& (FS3) flexible schedule & {$[31]$} \\
Facility service & (FA1) meal service & {$[16]$} \\
(FA) & (FA2) inflight cabin comfort & \\
& (FA3) well-designed of website & {$[17]$} \\
Customization & (CS1) Pleasant & {$[31]$} \\
(CS) & (CS2) Reliable & {$[19]$} \\
& (CS3) Timely and accurate & {$[14]$} \\
Word of mouth & (WOM1) Influenced my evaluation & {$[18]$} \\
(WOM) & (WOM2) Influenced my attitude & {$[32]$} \\
Satisfaction & (SAT1) alternate choice & {$[30]$} \\
(SAT) & (SAT2) prompt on-site queuing & {$[14]$} \\
& (SAT3) appealing purchasing & {$[18]$} \\
Intention & (SAT4) clear website pricing list & {$[32]$} \\
(INT) & (INT1) willing choice by low price & {$[31]$} \\
& (INT2) high intention possibility & \\
\hline \hline
\end{tabular}

\subsubsection{Factor loading as item reliability}

Based on smart PLS analysis, factor loadings of respective items were extracted as Table 2 which indicated high correlations between the items and the corresponding constructs. (with factor loading $>0.6$ ) Nevertheless, two items were deleted due to low loading. One is from the dimension of Assurance with factor loading 0.385 and the other one from the dimension of facility with 0.475 . Factor loading, lower than 0.6 , means substantial cross loadings or correlated error terms. The value of factor loading should be bigger than 0.50 as better credibility [33]. After items modified, the model then demonstrated a better analysis result.

\subsection{Data Collection and Samples}

The questionnaires were targeted to the passengers or possible passengers on LCCs. We prefer to design a simulation of LCC model. As we understand, all LCCs' operations are performed through Internet platform. No matter a passenger wants to book a flight and purchases electronic ticket, even meal added purchased from Internet. Therefore, we posted the questionnaire on the Internet platform, via m3q questionnaire website and Ptt BBS (Bulletin Board System). In order to stimulate Internet surfer's complete answers, we provide game points as a reward. After three months' collection, we finalized with 327 questionnaires and 
ended with 284 usable samples.

Table 2. Statistical Summary: Factor Loading Analysis

\begin{tabular}{|c|c|c|c|}
\hline \multirow[t]{2}{*}{ Factor and variables } & \multicolumn{2}{|c|}{ Descriptive statistics } & \multirow[t]{2}{*}{ loading } \\
\hline & $\mathrm{X}$ & Std & \\
\hline \multicolumn{4}{|l|}{ Assurance } \\
\hline (AS1) Employees have knowledge to answer questions & 3.72 & 1.076 & 0.850 \\
\hline (AS2) Safety is an essential requirement & 4.02 & 1.137 & 0.844 \\
\hline 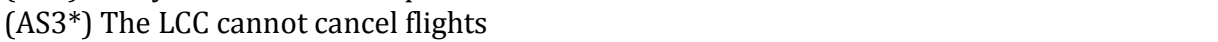 & 4.09 & 1.003 & 0.385 \\
\hline \multicolumn{4}{|l|}{ Customization } \\
\hline (CS1) Clean and comfortable interior/air conditioner/ seats & 3.67 & 1.095 & 0.801 \\
\hline (CS2) website with informative publicities & 3.72 & 1.105 & 0.795 \\
\hline (CS3) easy-operational website in purchasing tickets & 3.89 & 1.028 & 0.802 \\
\hline \multicolumn{4}{|l|}{ Facility service } \\
\hline (FA1) in-flight meal on purchasing demand & 3.94 & .957 & 0.651 \\
\hline (FA2) Individual attention and provide passengers' specific needs, like wheel-chair service & 4.31 & .803 & 0.808 \\
\hline (FA3 ${ }^{*}$ ) availability of travel related partners/package & 3.53 & 1.017 & 0.475 \\
\hline (FA4) availability of frequent flyer program & 4.39 & .765 & 0.837 \\
\hline \multicolumn{4}{|l|}{ Flight schedule } \\
\hline (FS1) availability of flight transfer service & 3.77 & 1.025 & 0.688 \\
\hline (FS2) availability of various destinations & 4.25 & .884 & 0.860 \\
\hline (FS3) convenient flight schedule & 3.93 & 1.054 & 0.730 \\
\hline \multicolumn{4}{|l|}{ Price } \\
\hline (PR1) Low price is priority concern & 4.38 & .946 & 0.838 \\
\hline (PR2) interested in bargains and promotion & 4.41 & .926 & 0.852 \\
\hline (PR3) when choosing a LCC, I compare prices & 4.18 & 1.033 & 0.809 \\
\hline \multicolumn{4}{|l|}{ Satisfaction } \\
\hline (SA1) an alternate wise choice when I travel & 4.32 & .917 & 0.832 \\
\hline (SA2) When choosing a LCC, I am happy with efficient check-in and prompt service & 3.73 & 1.073 & 0.699 \\
\hline (SA3) I am satisfied with the appealing price and attracted by the promotion & 4.07 & .954 & 0.768 \\
\hline (SA4) I am satisfied with how the LCC lists out publicly the cost items & 3.93 & 1.015 & 0.731 \\
\hline \multicolumn{4}{|l|}{ Word of mouth } \\
\hline (WM1) I will choose the LCC if my friends recommend it. & 3.86 & 1.106 & 0.975 \\
\hline (WM2) I will choose the LCC if my family and relatives recommend it. & 3.85 & 1.097 & 0.966 \\
\hline \multicolumn{4}{|l|}{ Intention } \\
\hline (INT1) I will select a LCC if the price increases. & 4.00 & 1.115 & 0.829 \\
\hline (INT2) If any possible chance to fly with a LCC, I would like to try flying with a LCC. & 4.22 & 1.010 & 0.858 \\
\hline (INT3) I would select the same LCC again if I am going to fly another time. & 3.65 & 1.138 & 0.840 \\
\hline
\end{tabular}

Table 3. Demographic Profile of Survey Respondents $N=284$

\begin{tabular}{|c|c|c|c|}
\hline & variables & usable cases & \\
\hline \multirow[t]{2}{*}{ Gender } & male & 166 & 58.5 \\
\hline & female & 118 & 41.5 \\
\hline \multirow[t]{4}{*}{ age } & $20-29$ & 164 & 57.7 \\
\hline & $30-39$ & 68 & 23.9 \\
\hline & $40-49$ & 31 & 10.9 \\
\hline & $>49$ & 21 & 7.4 \\
\hline \multirow[t]{3}{*}{ edu } & High school & 11 & 3.9 \\
\hline & Univ & 191 & 67.3 \\
\hline & Graduate & 82 & 28.9 \\
\hline \multirow[t]{4}{*}{ income } & $<20,000$ & 59 & 20.8 \\
\hline & $20,000-40,000$ & 115 & 40.5 \\
\hline & $40,000-60,000$ & 72 & 25.4 \\
\hline & $>60,000$ & 38 & 13.4 \\
\hline
\end{tabular}

The Table 3 elicits the sample demographic description. The gender compiled is not much different as 
male $58.5 \%$ and female $41.5 \%$. Somehow, the men take longer time in Internet than the women. Also the highest percentage $(57.7 \%)$ of respondents is aged between 20 and 29 years old, following is the second higher rate $(23.9 \%)$ of age between 30 and 39 years old. It's obliviously described the-frequent-Internet users who are young aged group. This is consistent with the studies of airline Internet users [15], [30]. The highest income rate of percentage (40.5\%) is between NTD20,000 and NTD40,000. It implied the saying of the young-aged group favoring in bargain hunting value for money [30]. It doesn't only imply the age group's preferences of Internet, but also indicates the main reason to bargain with LCC; that is, money cost comparing with the income shortage. In Taiwan, the income is based on low level estimation. The social and economic development is bias to provide lower than before.

\subsection{Data Analysis}

Considering the limited samples size, total two hundred and eighty-four valid respondents, PLS -SEM (partial least square) was adopted for data analysis. PLS-SEM is an increasingly used data analysis method [34], [35]. The PLS 2.0 algorithm and bootstrapping for re-sampling was adopted for coefficient estimation. The hypotheses and structural model were significantly evaluated in data analysis. By the analysis of PLS-SEM, this model was conducted respectively at two aspects. First is for descriptive analysis, statistical means, standard deviations and correlations for all constructs. Secondly, the model constructs were analyzed to verify path hypothesis and relationships among the constructs.

\subsubsection{Descriptive analysis}

Table 4 presents the respondents overall concepts toward LCCs. Generally speaking, the responses are positive (as all on a five-point scale) from 3.76 to 4.32. Comparing with other constructs, customization, with mean score 3.76 has the least consideration, which means customization, equally as customer service, was not the considering factor for the passengers choosing LCC. Price (4.32) with highest mean score comes to the important issue for LCC. In addition, with SD 1.1 on assurance factor, it indicates that respondents tend to have extreme views about LCC assurance dimension.

Table 4. Construct Mean, SD and Correlations

\begin{tabular}{lcccccccccccc}
\hline \multicolumn{1}{c}{ Constructs } & Mean & \multicolumn{2}{c}{ SD } & \multicolumn{1}{c}{1} & 2 & 3 & 4 & 5 & 6 & 7 & 8 \\
\hline 1. ASSURANCE & 3.87 & 1.11 & 1.000 & & & & & & & \\
2. CUSTOMIZATION & 3.76 & 1.08 & 0.287 & 1.000 & & & & & & \\
3. FACILITY SERVICE & & 4.21 & 0.84 & 0.472 & 0.405 & 1.000 & & & & & \\
4. FLIGHT SCHEDULE & 3.98 & 0.99 & 0.433 & 0.485 & 0.534 & 1.000 & & & \\
5. INTENTION & 3.96 & 1.09 & 0.309 & 0.112 & 0.306 & 0.346 & 1.000 & & \\
6. PRICE & 4.32 & 0.97 & 0.413 & 0.171 & 0.446 & 0.382 & 0.503 & 1.000 & & \\
7. SATISFACTION & 4.01 & 0.99 & 0.431 & 0.187 & 0.443 & 0.389 & 0.666 & 0.617 & 1.000 & \\
8. WORD OF MOUTH & 3.86 & 1.10 & 0.298 & 0.197 & 0.388 & 0.320 & 0.637 & 0.467 & 0.557 & 1.000 \\
\hline
\end{tabular}

\subsubsection{Correlations}

Correlations among customization and assurance, intention, price, satisfaction, word of mouth dimensions revealed that the correlation was relatively weak. Secondly, facility service and flight schedule show better correlations among other constructs with about medium number $>0.40$. Obviously price, satisfaction, word-of-mouth and intention have high related correlations.

\subsubsection{Convergent validity}

On PLS analysis, convergent validity was applied to test the consistency that multiple items present in measuring the same construct. Also unidimensionality, average variance extracted (AVE), and composite reliability (CR) are proper indicators of measuring convergent validity. For the unidimensionality, the factor loading $(>0.5)$ and $t$-value $(>1.96)$ of items must be qualified (The Table 5). As the Table 6 presented, 
after deleting two items (factor loading $<0.5$ ), all the items for the constructs were qualified for factor loading $>0.5$, t-value > 1.96 [36]-[38]. Moreover, the consistency can be proven on the AVE, CR or Cronbach's $\alpha$ of convergent validity on the Table 6. All the constructs had the AVE values higher than 0.5 (AVE function similar to communality) and CR values higher than 0.7 (Cronbach's $\alpha$ values $>0.6$ similar to CR function) which points out acceptable convergent validity of measurements [36], [39].

Table 5. Statistical Summary: $\mathrm{t}$-Value and Reliability Analysis with $\mathrm{N}=284$ (Loading < 0.6 Delete the Item)

\begin{tabular}{|c|c|c|c|c|}
\hline Factor and variables & loading & $t$-value & $\begin{array}{l}\text { Composite } \\
\text { Reliability }\end{array}$ & $\begin{array}{c}\text { Cronbachs } \\
\text { Alpha }\end{array}$ \\
\hline Assurance & & & 0.847 & 0.639 \\
\hline AS1 & 0.850 & 23.918 & & \\
\hline AS2 & 0.844 & 25.509 & & \\
\hline Customization & & & 0.841 & 0.722 \\
\hline $\mathrm{CS} 1$ & 0.801 & 6.059 & & \\
\hline $\mathrm{CS} 2$ & 0.795 & 6.200 & & \\
\hline $\mathrm{CS} 3$ & 0.802 & 6.031 & & \\
\hline Facility service & & & 0.819 & 0.664 \\
\hline FA1 & 0.651 & 11.247 & & \\
\hline FA2 & 0.808 & 17.844 & & \\
\hline FA4 & 0.837 & 23.522 & & \\
\hline Flight schedule & & & 0.806 & 0.649 \\
\hline FP1 & 0.688 & 10.230 & & \\
\hline FP2 & 0.860 & 27.246 & & \\
\hline FP3 & 0.730 & 11.441 & & \\
\hline PRICE & & & 0.872 & 0.780 \\
\hline PR1 & 0.838 & 26.169 & & \\
\hline PR2 & 0.852 & 27.829 & & \\
\hline PR3 & 0.809 & 28.877 & & \\
\hline Satisfaction & & & 0.844 & 0.758 \\
\hline SA1 & 0.832 & 36.408 & & \\
\hline SA2 & 0.699 & 13.794 & & \\
\hline SA3 & 0.768 & 19.296 & & \\
\hline SA4 & 0.731 & 15.651 & & \\
\hline Word of Mouth & & & 0.970 & 0.939 \\
\hline WM1 & 0.975 & 175.92 & & \\
\hline WM2 & 0.966 & 91.857 & & \\
\hline Intention & & & 0.880 & 0.795 \\
\hline INT1 & 0.829 & 26.838 & & \\
\hline INT2 & 0.858 & 40.868 & & \\
\hline INT3 & 0.840 & 22.301 & & \\
\hline
\end{tabular}

Table 6. Convergent Validity

\begin{tabular}{lllcccc}
\hline & AVE & $\begin{array}{c}\text { Composite } \\
\text { Reliability }\end{array}$ & $\mathrm{R}^{2}$ & $\begin{array}{c}\text { Cronach's } \\
\text { Alpha }\end{array}$ & Communality & Redundancy \\
\hline ASSURANCE & 0.735 & 0.847 & & 0.639 & 0.735 \\
CUSTOMIZATION & 0.639 & 0.841 & 0.722 & 0.639 & \\
FACILITY SERVICE & 0.604 & 0.819 & & 0.664 & 0.604 & \\
FLIGHT SCHEDULE & 0.582 & 0.806 & & 0.649 & 0.582 & 0.387 \\
INTENTION & 0.710 & 0.880 & 0.546 & 0.795 & 0.710 & 0.253 \\
PRICE & 0.694 & 0.872 & & 0.780 & 0.694 & 0.292 \\
SATISFACTION & 0.576 & 0.844 & 0.439 & 0.758 & 0.576 & 0.942 \\
WORD OF MOUTH & 0.942 & 0.970 & 0.310 & 0.939 & & \\
\hline
\end{tabular}

Fig. 2 shows the model algorithm result by PLS. In the reflective index, the inner constructs $\mathrm{R}^{2}$ value (coefficient of determination) presents the construct model validity. $\mathrm{R}^{2}>0.67$ has the empirical value and $\mathrm{R}^{2} \fallingdotseq 0.33$ means medium justification and $\mathrm{R}^{2} \fallingdotseq 0.19$ shows weak explanation for the model validity [37] Word of mouth $\mathrm{R}^{2}=0.310$ and Satisfaction $\mathrm{R}^{2}=0.439$ and Intention $\mathrm{R}^{2}=0.546$ are all about medium level qualified to explain the model validity. Another model construct can be testified by Redundancy analysis. The higher value of Redundancy means better model. Because GoF (Goodness of Fit) presents model 
validity, the value of square root of Redundancy equals GOF (GoFsmall=0.1, GoFmedium $=0.25$, GoFlarge $=0.36$ ) [40]. The Intention GoF $=0.622$, Satisfaction GoF $=0.50$ and Word of Mouth GoF $=0.54$ (on Table 6) all indicate large value as good model validity.

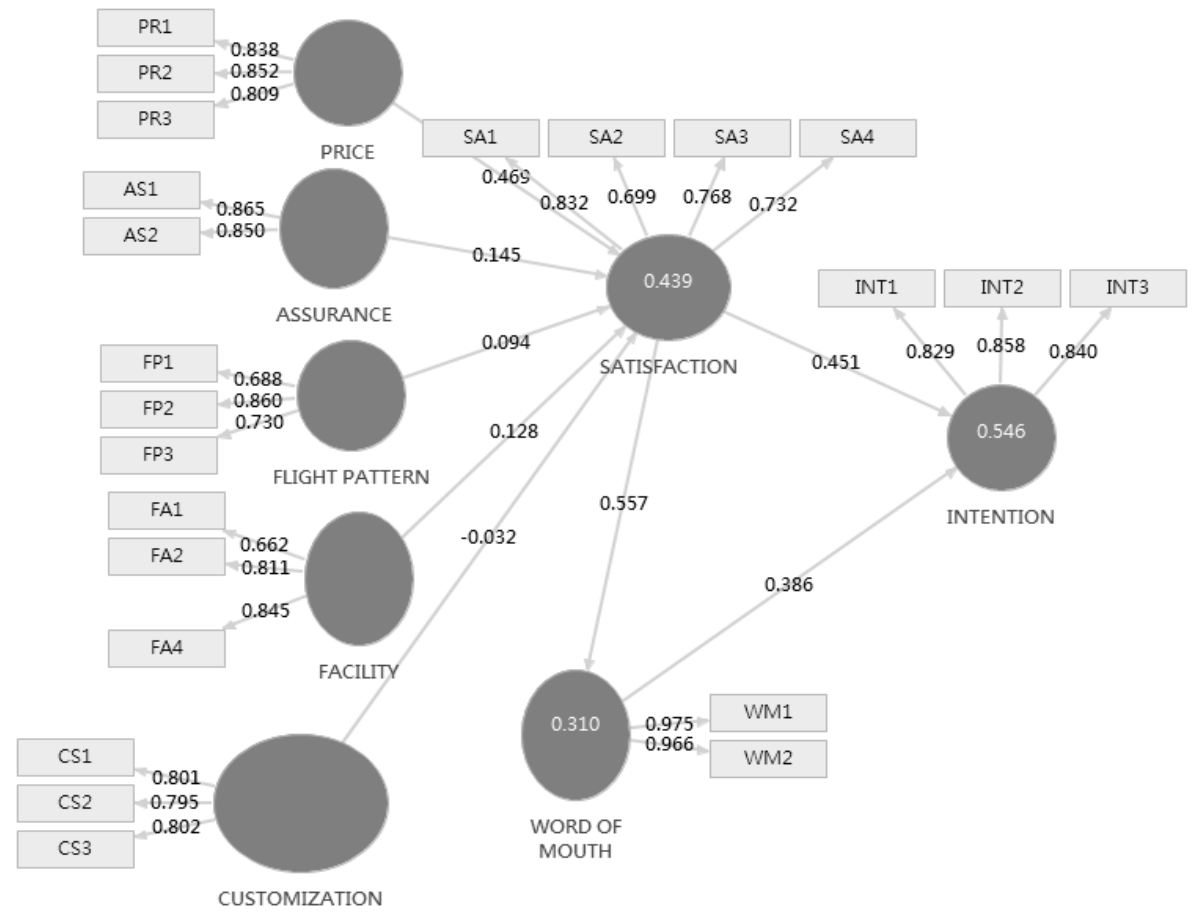

Fig. 2. Model algorithm result.

\subsubsection{Discriminate validity}

For the measurement of discriminate validity, the correlations between different constructs should be lower when compared with their own extracted variance values. The average variance extracted (AVE) and factor loading can be used to evaluate discriminate validity [33]. That is, the root square of AVE should be higher than the square of correlation coefficients with other constructs [39]. In Table 7, the square roots of AVEs (the block letter numbers) were all higher than the correlation coefficients with other constructs. Also the factor loading of each item should be higher on its principal constructs comparing with other loading factors on the cross loading list (In Appendix A Cross-loading factor, the block letter numbers are the own item factor loading). In all consumption, the results suggested good measurement properties for all constructs.

Table 7. Discriminate Validity (Fornell-Larcker Criterium)

\begin{tabular}{|c|c|c|c|c|c|c|c|c|c|}
\hline & AVE & CS & Ff & FP & & INT & PR & SAT & WM \\
\hline ASSURANCE & 0.735 & 0.857 & & & & & & & \\
\hline CUSTOMIZATION & 0.639 & 0.287 & 0.799 & & & & & & \\
\hline FACILITY & 0.604 & 0.472 & 0.405 & 0.777 & & & & & \\
\hline FLIGHT PATTERN & 0.582 & 0.433 & 0.485 & 0.534 & 0.763 & & & & \\
\hline INTENTION & 0.710 & 0.309 & 0.112 & 0.306 & 0.346 & 0.842 & & & \\
\hline PRICE & 0.694 & 0.413 & 0.171 & 0.446 & 0.382 & 0.503 & 0.833 & & \\
\hline SATISFACTION & 0.576 & 0.431 & 0.187 & 0.443 & 0.389 & 0.666 & 0.617 & 0.759 & \\
\hline WORD OF MOUTH & 0.942 & 0.298 & 0.197 & 0.388 & 0.320 & 0.637 & 0.467 & 0.557 & 0.971 \\
\hline
\end{tabular}

\subsubsection{Path analysis}

After suitable measurement of convergent validity and discriminate validity, the path analysis was 
applied to empirically justify the hypotheses. Table 8 shows the PLS-SEM analysis result. $P$ values indicate the correlations among the constructs. As the *:t-value $>1.96$, at $p<0.05 ; \quad{ }^{* *}: \mathrm{t}>2.58$ at $p<0.01 ; \quad{ }^{* * *}: \mathrm{t}>3.29$ at $p<0.001$, the results indicate that all the hypotheses were not rejected except FLIGHT PATTERN $\rightarrow$ SATISFACTION, FACILITY $\rightarrow$ SATISFACTION, CUSTOMIZATION $->$ SATISFACTION. Figure 3 shows clearer path hypotheses with t-value.

Table 8. Bootstrapping with t-Value

\begin{tabular}{|c|c|c|c|c|c|}
\hline & $\begin{array}{l}\text { Original } \\
\text { Sample (0) }\end{array}$ & $\begin{array}{l}\text { Sample Mean } \\
\text { (M) }\end{array}$ & $\begin{array}{l}\text { Standard Error } \\
\text { (STERR) }\end{array}$ & $\begin{array}{l}\text { T Statistics } \\
(\mid 0 / \text { STERR } \mid)\end{array}$ & $\begin{array}{c}P \\
\text { Values }\end{array}$ \\
\hline PRICE-------------> SATISFACTION & 0.469 & 0.471 & 0.066 & $7.079^{* * *}$ & 0.000 \\
\hline ASSURANCE------> SATISFACTION & 0.145 & 0.142 & 0.061 & $2.392^{*}$ & 0.017 \\
\hline FLIGHT PATTERN-> SATISFACTION & 0.094 & 0.097 & 0.080 & 1.176 & 0.240 \\
\hline FACILITY ----------> SATISFACTION & 0.128 & 0.123 & 0.071 & 1.793 & 0.073 \\
\hline CUSTOMIZATION -> SATISFACTION & -0.032 & -0.018 & 0.057 & 0.568 & 0.570 \\
\hline SATISFACTION --------> INTENTION & 0.451 & 0.456 & 0.068 & $6.623^{* * *}$ & 0.000 \\
\hline SATISFACTION->WORD OF MOUTH & 0.557 & 0.557 & 0.045 & $12.308^{* * *}$ & 0.000 \\
\hline WORD OF MOUTH -----> INTENTION & 0.386 & 0.383 & 0.062 & $6.215^{* * *}$ & 0.000 \\
\hline
\end{tabular}

$*: t$-value $>1.96, p<0.05 ;{ }^{* *}: t>2.58, p<0.01 ;{ }^{* * *}: t>3.29, p<0.001$

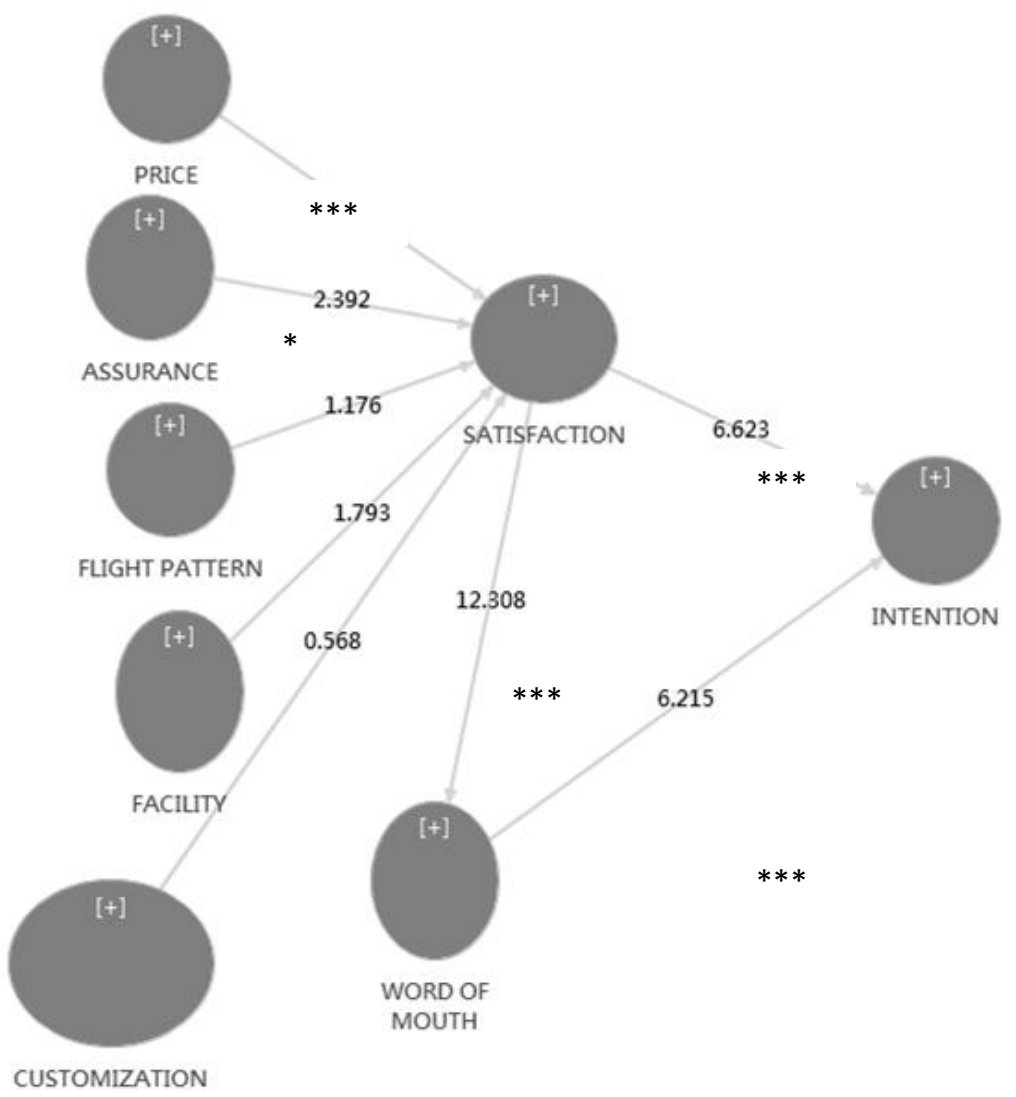

Fig. 3. Model path analysis.

In summary sort, the hypotheses test result was listed on Table 9. Price is strongly related to Satisfaction. The price of LCC has significant impact on satisfaction. Assurance also supported the impact on Satisfaction. However, flight schedule, facility service and customization were all rejected. All the above kind related to service aspects were not considered to influence satisfaction. Thus, satisfaction has significant impact on purchasing intention while satisfaction also strongly influenced word of mouth. In addition, word of mouth has obvious and significant impact on purchasing intention. 
Table 9. Summary of Testing of Hypotheses

\begin{tabular}{llrl}
\hline Predictor variables & Criterion variables & $\begin{array}{r}\text { Hypothesized } \\
\text { relationship }\end{array}$ & $\begin{array}{l}\text { Standardized coefficient } \\
(\beta)\end{array}$ \\
\hline PRICE & SATISFACTION & Strongly supported & $7.079^{* * *}$ \\
ASSURANCE & SATISFACTION & supported & $2.392^{*}$ \\
FLIGHT PATTERN & SATISFACTION & Not supported & 1.176 \\
FACILITY & SATISFACTION & Not supported & 1.793 \\
CUSTOMIZATION & SATISFACTION & Not supported & 0.568 \\
SATISFACTION & INTENTION & Strongly supported & $6.623^{* * *}$ \\
SATISFACTION & WORD OF MOUTH & Strongly supported & $12.308^{* * *}$ \\
WORD OF MOUTH & INTENTION & Strongly supported & $6.215^{* * *}$ \\
\hline
\end{tabular}

\section{Discussion}

Aware of LCC passengers satisfaction and to stimulate purchasing intention are important for airlines strategy. The most efficient method to attain satisfaction of LCC passengers in Taiwan is through competitive airfare ticket price. As our introduction for LCC in Taiwan, LCCs just step into Taiwan for not more than 10 years and so far there are only fourteen LCCs operating business in Taiwan route. The first LCC set up by Taiwan Corporation just ran on September, 2014, named as Tigerair. In order to understand Taiwan market, knowing the key factors are essential. In our study, Taiwanese concern "price" most. The main attraction for LCC passengers is much discounted and attractive airfare ticket purchased on the Internet. Another significant influencing factor is Assurance to Satisfaction which involve about flight safety. Any aircraft damage in the Air will cause tragically tremendous casualty. Flight safety if ever there was one should be top priority.

There are five exogenous variables (price, assurance, flight pattern, facility, and customization). Generally speaking, flight pattern, facility and customization can be related to service. The above can be improved to enhance passengers' satisfaction and gain their expectation, that is, accomplishments of service. Nevertheless, unlike other studies, service is highly associated with satisfaction [29]; or extension of service, service recovery, strongly enhanced passengers satisfaction than other factors [11], [16], [41], [42]. With same type of sample respondents (most of them are young and middle-aged passengers), the concerning factors summarized to be different issue. Word of mouth, satisfaction and purchasing intention are all significantly associated.

The characteristic of ethic concept in Taiwan seemingly enlightens the importance of word of mouth. Satisfaction directly influenced word of mouth with high positive inclination. Word of mouth as endogenous of satisfaction plays an important factor in influencing passengers' intention. People in Taiwan incline to believe or follow others' experiences. No matter passengers with experiences of LCCs or others' recommendation. It means that if the respondents are satisfied with LCCs, they will recommend LCCs to their friends. Otherwise, even heard from others' voluble experiences of LCCs, people are very possible to use LCCs. While satisfaction directly influenced purchasing intention, people significantly will use LCCs as their traveling facility if the satisfaction meets their expectation or if friends highly recommend LCC. Thus, viewing the whole model, Price can be regarded as indirectly influencing purchasing intention. Price significantly influenced satisfaction and then to purchasing intention. The results of this study provide useful insights into the behaviors of LCCs in Taiwan.

\section{Implications, Limitations and Further Research}

This study presents a different aspect and insight of LCC passengers' behavior in Taiwan. Different from others' studies with all positive factors, especially service enhancement [11], [16], [29], [42], [43], the strongest factors are price and word of mouth, and assurance is the second concern. LCC strategy deciders should put more effort in pricing strategy and competitive bargain to attract Taiwan passengers' 
preferences. The marketing strategy might focus on how to propagate LCC attraction. To make good use of network or even virus-marketing, like Facebook, twitter and blog. Those are representatives of word of mouth in speeding publication.

Secondly flight safety should be LCC's another important issue. Some air flight accidents occasionally occur in Taiwan. They definitely brand traumatic memory in their life-long experience. LCC should emphasize their flight safety and guarantee to win passengers' trust. For the customized service and flight slot, LCC might not spend too much percentage of advertisement for unbalanced cost at the end.

Nevertheless, there are still some limited foundings in this study. First, the respondents might be more if we took a longer time in collecting the sample size. However, lack of network virtual gift, it became hard to gain authentic and complete respondents without gift. Secondly, in order to intimate the LCC business model, our study chose to imply the Network survey instead of paper survey form. It might lose the chance to scrutinize the respondents' facial expression and face-to-face observation. The next time researcher might consider paper survey and network survey at the same to prove better implication.

\section{Appendix}

Cross-Loadings of All Constructs

\begin{tabular}{lcccccccc}
\hline & AS & CS & FA & FP & INT & PR & SAT & WOM \\
\hline AS1 & $\mathbf{0 . 8 6 5}$ & 0.329 & 0.398 & 0.407 & 0.314 & 0.316 & 0.378 & 0.351 \\
AS2 & $\mathbf{0 . 8 5 0}$ & 0.160 & 0.412 & 0.334 & 0.215 & 0.394 & 0.361 & 0.155 \\
CS1 & 0.179 & $\mathbf{0 . 8 0 1}$ & 0.316 & 0.391 & 0.044 & 0.091 & 0.121 & 0.155 \\
CS2 & 0.212 & $\mathbf{0 . 7 9 5}$ & 0.241 & 0.401 & 0.126 & 0.088 & 0.143 & 0.157 \\
CS3 & 0.279 & $\mathbf{0 . 8 0 2}$ & 0.397 & 0.375 & 0.092 & 0.209 & 0.174 & 0.160 \\
FA1 & 0.382 & 0.352 & $\mathbf{0 . 6 6 2}$ & 0.313 & 0.176 & 0.279 & 0.328 & 0.364 \\
FA2 & 0.326 & 0.261 & $\mathbf{0 . 8 1 1}$ & 0.449 & 0.206 & 0.283 & 0.332 & 0.208 \\
FA4 & 0.388 & 0.328 & $\mathbf{0 . 8 4 5}$ & 0.473 & 0.320 & 0.463 & 0.369 & 0.330 \\
FP1 & 0.181 & 0.428 & 0.323 & $\mathbf{0 . 6 8 8}$ & 0.209 & 0.236 & 0.205 & 0.217 \\
FP2 & 0.356 & 0.312 & 0.455 & $\mathbf{0 . 8 6 0}$ & 0.320 & 0.382 & 0.374 & 0.256 \\
FP3 & 0.425 & 0.427 & 0.428 & 0.730 & 0.243 & 0.227 & 0.277 & 0.263 \\
INT1 & 0.264 & 0.082 & 0.234 & 0.361 & $\mathbf{0 . 8 2 9}$ & 0.447 & 0.545 & 0.523 \\
INT2 & 0.275 & 0.131 & 0.365 & 0.266 & $\mathbf{0 . 8 5 8}$ & 0.478 & 0.614 & 0.532 \\
INT3 & 0.242 & 0.068 & 0.167 & 0.249 & $\mathbf{0 . 8 4 0}$ & 0.343 & 0.520 & 0.556 \\
PR1 & 0.337 & 0.108 & 0.373 & 0.275 & 0.372 & $\mathbf{0 . 8 3 8}$ & 0.491 & 0.395 \\
PR2 & 0.301 & 0.138 & 0.357 & 0.261 & 0.353 & $\mathbf{0 . 8 5 2}$ & 0.520 & 0.385 \\
PR3 & 0.393 & 0.178 & 0.385 & 0.414 & 0.527 & $\mathbf{0 . 8 0 9}$ & 0.528 & 0.386 \\
SA1 & 0.351 & 0.134 & 0.427 & 0.369 & 0.579 & 0.618 & $\mathbf{0 . 8 3 2}$ & 0.450 \\
SA2 & 0.297 & 0.146 & 0.233 & 0.190 & 0.371 & 0.342 & $\mathbf{0 . 6 9 9}$ & 0.420 \\
SA3 & 0.314 & 0.175 & 0.365 & 0.364 & 0.630 & 0.489 & $\mathbf{0 . 7 6 8}$ & 0.438 \\
SA4 & 0.354 & 0.110 & 0.282 & 0.211 & 0.383 & 0.367 & $\mathbf{0 . 7 3 2}$ & 0.381 \\
WM1 & 0.323 & 0.211 & 0.404 & 0.336 & 0.647 & 0.495 & 0.591 & $\mathbf{0 . 9 7 5}$ \\
WM2 & 0.250 & 0.169 & 0.346 & 0.282 & 0.585 & 0.405 & 0.481 & $\mathbf{0 . 9 6 6}$ \\
\hline & & & & & & &
\end{tabular}

\section{References}

[1] Chung, J. Y., \& Whang, T. (2011). The impact of low cost carriers on Korean Island tourism. Journal of Transport Geography, 19(6), 1335-1340.

[2] Dresner, M., Lin, J. C., \& Windle, R. (1996). The impact of low-cost carriers on airport and route competition. Journal of Transport Economics and Policies, 309-329.

[3] Dobruszkes, F. (2006). An analysis of European low-cost airlines and their networks. Journal of Transport Geography, 14(4), 249-264. 
[4] Davison, L., \& Ryley, T. (2010). Tourism destination preferences of low-cost airline users in the East Midlands. Journal of Transport Geography, 18(3), 458-465.

[5] Gustafson, P. (2012). Managing business travel: Developments and dilemmas in corporate travel management. Tourism Management, 33(2), 276-284.

[6] Klophaus, R. (2005). Frequent flyer programs for European low-cost airlines: Prospects, risks and implementation guidelines. Journal of Air Transport Management, 11(5), 348-353.

[7] Pearson, J., \& Merkert, R. Airlines-within-airlines: A business model moving East. Journal of Air Transport Management, 38, 21-26.

[8] Gillen, D., \& Lall, A. (2004). Competitive advantage of low-cost carriers: some implications for airports. Journal of Air Transport Management, 10(1), 41-50.

[9] Kumar. (2006). Strategies to fight low-cost rivals. Harvard Business Review,. 104-112. London: Harvard.

[10] Hofer, C., Windle, R. J., \& Dresner, M. E. (2008). Price premiums and low cost carrier competition. Transportation Research Part E: Logistics and Transportation Review, 44(5), 864-882.

[11] Lindenmeier, J., \& Tscheulin, D. K. (2008). The effects of inventory control and denied boarding on customer satisfaction: The case of capacity-based airline revenue management. Tourism Management, 29(1), 32-43.

[12] Marcus, B., \& Anderson, C. K. (2008). Revenue management for low-cost providers. European Journal of Operational Research, 188(1), 258-272.

[13] Schmidt, G. M. D., \& Cheryl, T. (2008). When is a disruptive innovation disruptive? J of PROD INNOV MANAG, 25, 347-369.

[14] Saha, G. C., \& Theingi. (2009). Service quality, satisfaction, and behavioural intentions. Managing Service Quality: An International Journal, 19(3), 350-372.

[15] O'Connell, J. F., \& Williams, G. (2005). Passengers' perceptions of low cost airlines and full service carriers: A case study involving Ryanair, Aer Lingus, Air Asia and Malaysia Airlines. Journal of Air Transport Management, 11(4), 259-272.

[16] Gilbert, D., \& Wong, R. K. C. (2003). Passenger expectations and airline services: A Hong Kong based study. Tourism Management, 24(5), 519-532.

[17] Parasuraman, A., Zeithaml, V., \& Berry, L. (1988). SERVQUAL: A multiple-item scale for measuring consumer perceptions of service quality. Journal of Retailing, 64(1), 12-40.

[18] Amaro, S., \& Duarte, P. (2015). An integrative model of consumers' intentions to purchase travel online. Tourism Management, 46, 64-79.

[19] Wen, Y. (2010). Positioning of international air passenger carriers using multidimensioanl scaling and correspondence analysis. Transportation Journal, 7-23.

[20] Zeithaml. (1988). Consumer perception of prices, quality and value: Aa means-end model and synthesis of evidence. Journal of Marketing, 52, 2-22.

[21] Berry. (2000). Cultivating service brand equity. Journal of the Academy of Marketing Science, 28(1), 128-137.

[22] Bitner. (1992). Servicescapes: The impact of physical surroundings on customesr and employees. Journal of marketing, 56, 57-71.

[23] Adler, N., Pels, E., \& Nash, C. (2010). High-speed rail and air transport competition: Game engineering as tool for cost-benefit analysis. Transportation Research Part B: Methodological, 44(7), 812-833.

[24] Lemmink, J. (2002). Employee behavior, feelings of warmth and customer perception in service encounters. International Journal of Retail \& Distribuition Management, 30(1), 18-33.

[25] Mun, W., \& Ghazali, M. (2011). Branding satisfaction in the airline industry: A comparative study of Malaysia Airlines and Air Asia. African Journal of Business Management, 5(8), 3410-3423. 
[26] Oliver. (1999). Whence consumer loyalty. Journal of marketing, 63, 33-44.

[27] La, Y. (2004). What influences the relationship between customer satisfactin and repurchase intention? Investigating the effects of adjusted expectations and customer loyalty. Psychology \& Marketing, 21(5), 351-373.

[28] Jayawardhena, C., et al. (2007). Outcomes of service encounter quality in a business-to-business context. Industrial Marketing Management, 36(5), 575-588.

[29] Lee, C. K., Yoon, Y. S., \& Lee, S.-K. (2007). Investigating the relationships among perceived value, satisfaction, and recommendations: The case of the Korean DMZ. Tourism Management, 28(1), 204-214.

[30] Akamavi, R. K., et al. (2015). Key determinants of passenger loyalty in the low-cost airline business. Tourism Management, 46, 528-545.

[31] Wu, H. C., \& Cheng, C.C. (2013). A hierarchical model of service quality in the airline industry. Journal of Hospitality and Tourism Management, 20, 13-22.

[32] Kim, M. J., Chung, N., \& Lee, C. K. (2011). The effect of perceived trust on electronic commerce: Shopping online for tourism products and services in South Korea. Tourism Management, 32(2), 256-265.

[33] Hair, J. F., Ringle, C. M., \& Sarstedt, M. (2012). Partial least squares: The better approach to structural equation modeling? Long Range Planning, 45(5-6), 312-319.

[34] Drengner, J. A. N., Gaus, H., \& Jahn, S. (2008). Does flow influence the brand image in event marketing? Journal of Advertising Research, 48(1), 138.

[35] Hsieh, J. J. P. R., \& Keil, M. A. (2008). Understanding digital inequality: comparing continued use behavioral models of the socio-economically advantaged and disadvantaged. MIS Quarterly, 32(1), 97-126.

[36] Bookstein, F. (1982). Two structural equation models: LISREL and PLS applied to consumer exit-voice theory. Journal of marketing Reserach, 440-452.

[37] Jarvis, M. P. (2003). Critical review of construct indicators and measurement model misspecification in marketing and consumer research. Journal of Consumer Research, 199-219.

[38] Yi, B. (1990). Assessing method variance in multitrait-multimethod matrices: The case of self-reported affect and perceptions at work. Journal of Applied Psychology, 75(5), 547-560.

[39] Fornell, L. (1981). Evaluating structural equation model with unobeservable variables and measurement error. Journal of Marketing Research, 39-50.

[40] Wetzels, M. S., Gaby, O., Oppen, C. (2009). Using PLS path modeling for assessing hierarchical construct models: Guidelines and empirical illustration. MIS Quarterly, 33(1), 177-195.

[41] Karatepe, O. M., \& Sokmen, A. (2006). The effects of work role and family role variables on psychological and behavioral outcomes of frontline employees. Tourism Management, 27(2), 255-268.

[42] Kim, H. B., Kim, T., Shin, S. W. (2009). Modeling roles of subjective norms and eTrust in customers' acceptance of airline B2C eCommerce websites. Tourism Management, 30(2), 266-277.

[43] Karatepe, O. M., et al. (2006). The effects of selected individual characteristics on frontline employee performance and job satisfaction. Tourism Management, 27(4), 547-560.

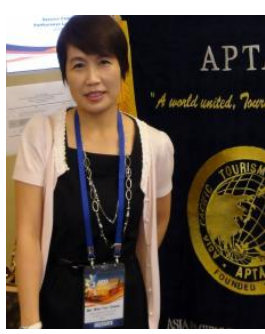

Cheng Tina is a doctoral candidate in the College of Management at National Kaohsiung First University of Science and Technology in Taiwan. She is also a lecturer in the International College of National Kaohsiung University of Hospitality and Tourism in Kaohsiung City, Taiwan. Her research interests are service quality, service satisfaction, service recovery, organizational performance and organizational e-learning education. 
Chen, Chen-Cheng is an assistant professor in the Department of Logistics Management at the National Kaohsiung First University of Science and Technology (NKFUST), Taiwan. She received his PhD degree in economics from Kyoto University in 1999, Japan. Her research interests include business administration, business economics, human resources management. 